\section{Efficacy of Therapeutic Plasma Exchange in Severe Immune Hemolytic Anemia Induced by a Carboplatin Desensitization Procedure}

Vilà-Nadal $\mathrm{G}^{1, *}$, Fiandor Román $\mathrm{A}^{1,2,3}$, Heredia Revuelto $\mathrm{R}^{1}$, Hernández-Maraver $\mathrm{D}^{4}$, Kerguelen Fuentes $\mathrm{AE}^{4}$, Ramírez García E $\mathrm{E}^{2,3,5,6}$, Cabañas Moreno R $\mathrm{R}^{1,2,3,7}$

${ }^{I}$ Allergy Unit, Hospital Universitario La Paz, Madrid, Spain

${ }^{2}$ Institute for Health Research (IdiPAZ), Madrid, Spain

${ }^{3}$ PIELenRed Consortium

${ }^{4}$ Department of Haematology, Transfusion Centre and Tissue Bank, Hospital Universitario La Paz, Madrid, Spain

${ }^{5}$ Pharmacology Department, Hospital Universitario La Paz, Madrid, Spain

${ }^{6}$ Pharmacology Department, School of Medicine, Universidad Autónoma de Madrid, Spain

${ }^{7}$ Centro de Investigación en Red de Enfermedades Raras (CIBERER, U754)

*Currently: Allergy \& Clinical Immunology, Royal Brompton Hospital, London, UK

J Investig Allergol Clin Immunol 2021; Vol. 31(2): 178-179 doi: 10.18176/jiaci.0634

Key words: Drug-induced immune hemolytic anemia. Immunohematology. Carboplatin. Therapeutic apheresis.

Palabras clave: Anemia hemolítica inmune inducida por fármaco. Inmunohematología. Carboplatino. Aféresis terapéutica.

A 37-year-old woman was diagnosed with ovarian papillary carcinoma at the age of 14 years (currently stage IV). She has since received multiple lines of chemotherapy, including 2 lines of carboplatin in 2000 and 2008.

In 2009, during the administration of the first cycle of carboplatin (third line of treatment), she developed general malaise, fever, palmar pruritus, and severe dyspnea. The drug infusion was discontinued, symptomatic treatment was administered, and the patient immediately recovered. She tolerated a further 5 cycles of carboplatin with premedication (dexchlorpheniramine and 6-methylprednisolone).

In 2016, the patient required treatment with carboplatin and was referred to our Allergy Department for evaluation. Prick and intradermal tests with carboplatin at $1 \mathrm{mg} / \mathrm{mL}$ were negative.

The first cycle of $395 \mathrm{mg}$ of carboplatin was tolerated following a desensitization protocol [1]. A 3-solution, 12step protocol was administered based on doubling drug doses by step, and the patient was premedicated with aspirin, prednisolone, cetirizine, and montelukast. Subsequent cycles were administered monthly under the same regimen. After the administration of the tenth cycle, she developed presyncope with fading vision. Her blood pressure was 90/60 $\mathrm{mmHg}$, as at baseline, and she was given serum therapy without improvement. She reported dysthermia and low back pain. She was transferred to the emergency department. Of note, the patient did not experience pruritus, angioedema, dyspnea, or other signs of an immediate hypersensitivity reaction.

In the emergency department, her oxygen saturation was stable, and she had a high axillary temperature $\left(37.8^{\circ} \mathrm{C}\right)$. Laboratory analysis disclosed the following: hemoglobin, $6.3 \mathrm{~g} / \mathrm{dL}$; total bilirubin, $3.9 \mathrm{mg} / \mathrm{dL}$; and lactate dehydrogenase (LDH), $2052 \mathrm{IU} / \mathrm{L}$. Blood tests from the previous 48 hours showed normal hemoglobin $(11.2 \mathrm{~g} / \mathrm{dL})$, total bilirubin (0.5 mg/dL), and LDH (200 IU/L).

She received 3 red blood cell transfusions and was started on a course of levofloxacin $500 \mathrm{mg}$ and methylprednisolone $250 \mathrm{mg}$. She developed an acute bilateral pulmonary thromboembolism 48 hours after administration of carboplatin and was admitted to the intensive care unit and treated with fibrinolysis. Cyclophosphamide, rituximab, intravenous immunoglobulin, and multiple transfusions of red blood cells were administered, reaching a peak hemoglobin level of $9 \mathrm{~g} / \mathrm{dL}$. On the following days, the hemoglobin dropped again to $6.5 \mathrm{~g} / \mathrm{dL}$, indicating persistent hemolysis.

Analysis of the patient's serum revealed her ABO group to be $\mathrm{O}$ and her $\mathrm{Rh}$ type to be positive. An indirect antiglobulin test using low-ionic-strength saline yielded a positive result, and a polyethylene glycol antibody identification test revealed an antibody reacting with all the commercially available group $\mathrm{O}$ antibody detection red cells (positive agglutination, score 5). A direct antiglobulin test was positive for polyspecific reagent (score 12) and $\mathrm{IgG}$ and $\operatorname{IgM}$ reagents (score 12). A positive anti-C $3 \mathrm{~d}$ result (score 11) confirmed activation of the complement system. Testing of serum and the eluate revealed autoantibody, and autologous adsorption ruled out the presence of underlying clinically significant alloantibodies. These initial results indicated that the patient had hemolytic anemia of immunological origin.

Drug-induced immune hemolysis was investigated to determine the drug's involvement in the destruction of the patient's red blood cells. Briefly, a solution of $0.88 \mathrm{mg} / \mathrm{mL}$ of carboplatin was prepared in phosphate-buffered saline at $\mathrm{pH}$ 7.0/7.4 (ie, same as that given to the patient). The patient's red blood cells (RBCs) were treated with the carboplatin solution (incubated at room temperature and at $37^{\circ} \mathrm{C}$ for 1 hour). Hemolysis occurred only when the serum was tested with carboplatin-treated RBCs, but not with untreated RBCs (ABO group $\mathrm{O}$ donor), thus enabling us to conclude that the patient had carboplatin-induced immune hemolytic anemia.

The half-life of carboplatin is 167 hours ( 7 days), meaning that the drug would be eliminated in 7 half-lives (48 days). Given the critical situation of the patient and the unresolved hemolysis, it was decided to perform therapeutic plasma exchange (TPE) (1900 cc).

After the treatment, the patient experienced a progressive increase in hemoglobin levels, reaching a peak of $11 \mathrm{~g} / \mathrm{dL}$. She was discharged within 13 days of admission.

Carboplatin is an alkylating agent that is widely used for the treatment of different types of cancer. Its main toxicity is myelosuppression, and anemia is common during treatment.

Protocols for desensitization to chemotherapeutics are used to address hypersensitivity reactions. They are tailored to the patient and protect against anaphylaxis.

Drug-induced immune hemolytic anemia is a rare disease with an estimated incidence of 1 case per 1 million patients 
per year $[2,3]$. Exposure to a specific drug induces a rapid fall in circulating RBCs via an immune-mediated process [3].

Laboratory findings include anemia, reticulocyte elevation, hyperbilirubinemia, low haptoglobin, and elevated LDH.

The reaction reported here corresponds to a type II reaction according to the Gell and Coombs classification. Type II reactions are mediated by the interaction of preformed IgG and IgM antibodies, with antigens present on the cell surface and other tissue components. There have been 7 reported cases of carboplatin-mediated hemolytic anemia [4-10]. Interestingly, 1 publication [4] reported a similar case with a combination of a type I IgE-mediated reaction and a type II IgG-mediated reaction to carboplatin occurring during desensitization. In the present case, IgM to carboplatin was also detected and had a severe clinical course requiring TPE.

Drug-induced immune hemolytic anemia has never been reported with the administration of the first cycle. Symptoms in all cases are similar, and it seems that low back pain is characteristic. Anti-IgG and anti-C3 antibodies were found in 6 of the cases [5-9], and the patient we report was the only one who had anti-IgM antibodies. None of the previous patients received TPE, 2 died, and 5 progressed well.

TPE removes large-molecular-weight substances such as antibodies from plasma, which is extracted while a replacement solution is being infused, thus maintaining volume and oncotic pressure. This approach aims to eliminate preformed antibodies and immunocomplexes and avoid tissue damage.

Drug-induced immune hemolytic anemia is a rare condition, although it can appear in patients receiving chemotherapy under desensitization schemes. Professionals administering chemotherapy should be aware of this condition.

To our knowledge, this is the second case of immune hemolytic anemia induced by carboplatin during a desensitization protocol.

The effectiveness of TPE in the present case leads us to recommend it for patients with severe drug-induced immune hemolytic anemia.

\section{Previous Presentations}

- 18/05/2017: Sociedad de Madrid y Castilla la Mancha (SMCLM) de Alergología e Inmunología Clínica. Madrid, Spain. Sesión clínica interhospitalaria. Name of the case: Reacción a carboplatino: una entre un millón (Reaction to carboplatin: one in a million) by Gemma Vilà-Nadal.

- 27/10/2017 “Simposio Internacional Aerobiología, Contaminación y Cambio Climático”. Murcia, Spain. Oral comunication: "Anemia hemolítica mediada por IgG e IgM con activación del complemento inducida por carboplatino en pauta de desensibilización (Hemolytic anemia IgG and IgM mediated with complement activation induced by carboplatin in a drug-desensitization program) by Gemma Vilà-Nadal.

\section{Acknowledgments}

We would like to thank all the persons from the different departments who helped during the diagnostic and therapeutic process of this complex case: Oncology, Hematology,
Emergency, Intensive Care, Pharmacology, and Allergy. We are also grateful to the patient.

\section{Funding}

The authors declare that no funding was received for the present study.

\section{Conflicts of Interest}

The authors declare that they have no conflicts of interest.

\section{References}

1. Lee CW, Matulonis UA, Castells MC. Rapid inpatient/ outpatient desensitization for chemotherapy hypersensitivity: standard protocol effective in 57 patients for 255 courses. Gynecol Oncol. 2005;99(2):393-9.

2. Petz LD, Garraty G. Acquired Immune Hemolytic Anemias. 2nd ed. Philadelphia: Churchill Livingstone. 2004.

3. Garraty, G. Immune hemolytic anemia associated with drug therapy. Blood Rev. 2010;24:143-50.

4. Pérez-Alzate $\mathrm{D}$, Blanca-López $\mathrm{N}$, Somoza $\mathrm{ML}$, Ruano $\mathrm{FJ}$ Montero GS, Penalva MJ, et al. Anaphylaxis and severe immune hemolytic anemia during the course of desensitization with carboplatin. Ann Allergy Asthma Immunol. 2018;120(4):442-3.

5. Maloisel F, Kurtz JE, Andres E, Gorodetsky C, Dufour P, Oberling F. Platin salts-induced hemolytic anemia: cisplatin- and the first case of carboplatin-induced hemolysis. Anticancer Drugs. 1995;6(2):324-6.

6. Marani TM, Trich MB, Armstrong KS, Ness PM, Smith J, Minniti $C$, et al. Carboplatin-induced immune hemolytic anemia. Transfusion. 1996;36(11-12):1016-8.

7. Dacha S, Reddivari AK, Latta S, Devidi M, Iroegbu N. Carboplatin Induced Fatal Autoimmune Hemolytic Anemia: First Reported Case. World J Oncol. 2010;1(4):173-5.

8. Betensky M, Witmer C, Fisher MJ, Nance S, Weiss MJ, Sesok-Pizzini DA. Immune hemolytic anemia with drug-induced antibodies to carboplatin and vincristine in a pediatric patient with an optic pathway glioma. Transfusion. 2014;54(11):2901-5.

9. Haley KM, Russell TB, Boshkov L, Leger RM, Garratty G, Recht $M$, et al. Fatal carboplatin-induced immune hemolytic anemia in a child with a brain tumor. J Blood Med. 2014;5:55-8.

10. Leger RM, Jain S, Nester TA, Kaplan H. Drug-induced immune hemolytic anemia associated with anti-carboplatin and the first example of anti-paclitaxel. Transfusion. 2015;55(12):2949-54.

Manuscript received February 13, 2020; accepted for publication July 24, 2020.

Rosario Cabañas Moreno Allergy Unit Hospital Universitario La Paz Paseo de la Castellana, 261 28046 Madrid, Spain

E-mail: charo.cabanas@gmail.com mrosario.cabanas@salud.madrid.org 